\title{
Building models for agricultural land fire prediction using remote sensed environmental data: a case study in Dien Bien Province, Vietnam (2003 - 2016)
}

\author{
Thu Thi Nguyen', 2, ${ }^{\text {, Thi Dieu Tran }}{ }^{2,3}$, Tran Vu Khanh Linh ${ }^{4}$, Thai Son Le ${ }^{1,}$ Ho Dang Phuc ${ }^{5}$ Trang \\ Thanh Pham ${ }^{1,2}$ \\ 1 Vietnam National University of Forestry(VNUF), Xuan Mai, Chuong My, Ha Noi, Vietnam \\ 2 Agricultural and Forestry Science, Murdoch University, 90 South Street, Murdoch, WA, Australia \\ ${ }^{3}$ National Agriculture Extension Center (NAEC), Ministry of Agriculture and Rural Development (MARD), \\ Hanoi, Vietnam \\ ${ }^{4}$ Nong Lam University - Ho Chi Minh City, Thu Duc, Ho Chi Minh City, Vietnam \\ ${ }^{5}$ Institute of Mathematics, Vietnam Academy of Science and Technology (VAST), 18 Hoang Quoc Viet, Cau Giay, \\ Ha Noi, Vietnam. \\ *Correspondence: thu.nguyen.2k14@gmail.com
}

\begin{abstract}
Agricultural land fires have been linked to various and adverse impacts on ecosystems, food security and the agriculture sector. Understanding the patterns and drivers of agricultural land fires is essential for effective agricultural land fire management. The key objectives of this study were to (1) analyze the temporal and spatial patterns of agricultural land fires using satellite remote sensed data, (2) assess a range of environmental conditions that could drive the occurrence of agricultural land fires, (3) determine the best model for predicting agricultural land fires and (4) determine the relative contribution of each environmental condition variable on the best predictive model. We used both univariate and multivariate regressions for the fire prediction capability of four independent environmental conditions (fuel, weather, topographic and anthropogenic). Analysis of historical satellite data revealed that agricultural land fires were more frequent than forested land fires. Our analyses also revealed that fuel condition was the most important variable for predicting agricultural land fires followed by weather, topographic and anthropogenic conditions. This study provides a novel multivariate model for predicting agricultural land fires that harbors the potential to improve agricultural land fire management and reduce fire risk within the agricultural sector.
\end{abstract}

\section{Keywords: Agricultural land, remote sensing, agricultural fire, fire predicting model}

\section{Introduction}

Agricultural land is one of the most important land use types and now accounts for nearly $40 \%$ of the Earth's surface following worldwide replacement of other land use types such as forests and grasslands ([1]. Agricultural land fires have scorched pasture, razed vineyards, destroyed livestock and are expected to challenge water resource capabilities [2]. While fires and climate change have already exhibited concurrent and negative impacts on the agriculture industry due to warming, low precipitation, and drought in dry-land areas like Australia [2], uncontrolled agricultural land fires in tropical regions like Vietnam and Indonesia have also been linked to various adverse impacts on ecosystems, food security and the agriculture sector [3]. Such agricultural land fires are widespread and account for $10 \%$ of the total fires that occur annually worldwide [4]; however, despite this global impact, our understanding of agriculture land fire patterns remains limited [5].

Fire ignition relies on several interacting variables such as weather and fuel conditions, topography and likelihood of an ignition source [6-10]. While fuel condition is a major determinant of fire occurrence [11], weather conditions strongly influence the likelihood of fire occurrence by causing conditions that are conducive to fuel drying (i.e., antecedent) as well as ignition, combustion and spread (i.e., ambient) [11]. Topography also exhibits strong influence on the likelihood of fire occurrence, intensity and severity by affecting localized weather patterns, atmospheric moisture and fuel a vailability [12-14]. Humans (i.e., anthropogenic conditions) are the main source of fire ignition 
[15], especially in regions where fire is used to clear agricultural land [16]. The determinants of agricultural land fires differ considerably from the determinants of forest fires [17, 18]; however, the unique determinants of agricultural land fires have, to date, received little attention within the scientific literature [17].

Satellite remote sensing has been used to accurately document and monitor fire occurrences worldwide for the past 20 years $[19,20]$. Given that the collection of detailed field data is time and labour intensive, and generally spans a limited temporal and geographic range, satellite collected datasets are becoming more commonly u tilized for fire prediction models (Caccamo et al., 2012; Litton \& Ellsworth, 2013). More specifically, the Moderate Resolution Imaging Spectroradiometer (MODIS) on the Terra and Aqua satellites of the National Aeronautics and Space Administration (NASA) Earth Observing System (EOS) has considerably improved our ability to detect fires from space $[3,5]$ and, in so doing, made MODIS a invaluable tool for monitoring agricultural land fires worldwide. Accordingly, long-term satellite remote sensing data can be used to construct models for accurate prediction and management of agricultural land fires by taking into account fuel, weather, topographic and anthropogenic conditions [21].

While the anthropogenic and environmental conditions that accurately predict forest fire occurrence throughout the world are well documented [22-24] investigations into those conditions that accurately predict agricultural land fires are limited [18] despite the influence of anthropogenic factors and unique regime characteristics of agricultural fires (e.g., fuel, seasonality, frequency and severity) [21]. This study used Dien Bien Province, Vietnam (2003 - 2016) as a case study to identify the temporal patterns and anthropogenic and environmental condition variables that harbour the capability to predict agricultural land fires. More specifically, the key objectives of this study were to: (1) analyse the temporal and spatial patterns of agricultural land fires using remote sensed data, (2) assess a range of anthropogenic and independent environmental conditions that could drive agricultural land fires, (3) determine the best model for predicting agricultural land fires and (4) determine the relative contribution of each variable on the best predictive model. Findings from this study can potentially lead to enhancement of agricultural land fire management practices and, in so doing, reduce fire risk within the agricultural sector.

\section{Materials and Methods}

\subsection{Study area}

Dien Bien province is located in the Northwest region of Vietnam $\left(20054^{\prime}-22^{03} 3^{\prime} \mathrm{N}, 102^{010^{\prime}}\right.$ $103036^{\prime} \mathrm{E}$ ) and spans 9,560 $\mathrm{km}^{2}$ [25] (Fig. 1). The province has an inland tropical monsoon climate with distinct wet and dry seasons (April to October and November to March) that are associated with high and low temperatures and humidity, respectively, as well as Foehn (i.e., hot and dry) wind during the Summer months [26]. The annual average temperature and sunshine range between $20-22.5^{\circ} \mathrm{C}$ and 1,700 - 2,100 hours, respectively. The landscape of Dien Bien varies in elevation $(200-1800 \mathrm{~m})$ due to the undulating northwest-to-southeast oriented mountains that are interspersed with streams and narrow valleys [27].

The economy of Dien Bien is predominantly based on agriculture with up to $85 \%$ of the population living in rural areas and financially dependent on agricultural (e.g., rice, corn and cattle) and foraging (e.g., mushrooms, honeybees, bamboo shoots, and rattans) practices (DienBien portal [27]. Agricultural and forested land accounts for $11.32 \%$ and $40 \%$ of total province, respectively [28, 29]; however, given population growth across recent decades, there is perpetual interest in agricultural land area expansion [30,31]. Such intense anthropogenic conditions cause a significant impact on the landscape, including human-induced fires for transforming naturally vegetated areas to pastures and croplands [30,31]. Management of agricultural land is particularly challenging in Dien Bien Province given the frequency of agricultural land fires, which is expected to increase under predicted climate change scenarios [28, 29]. 


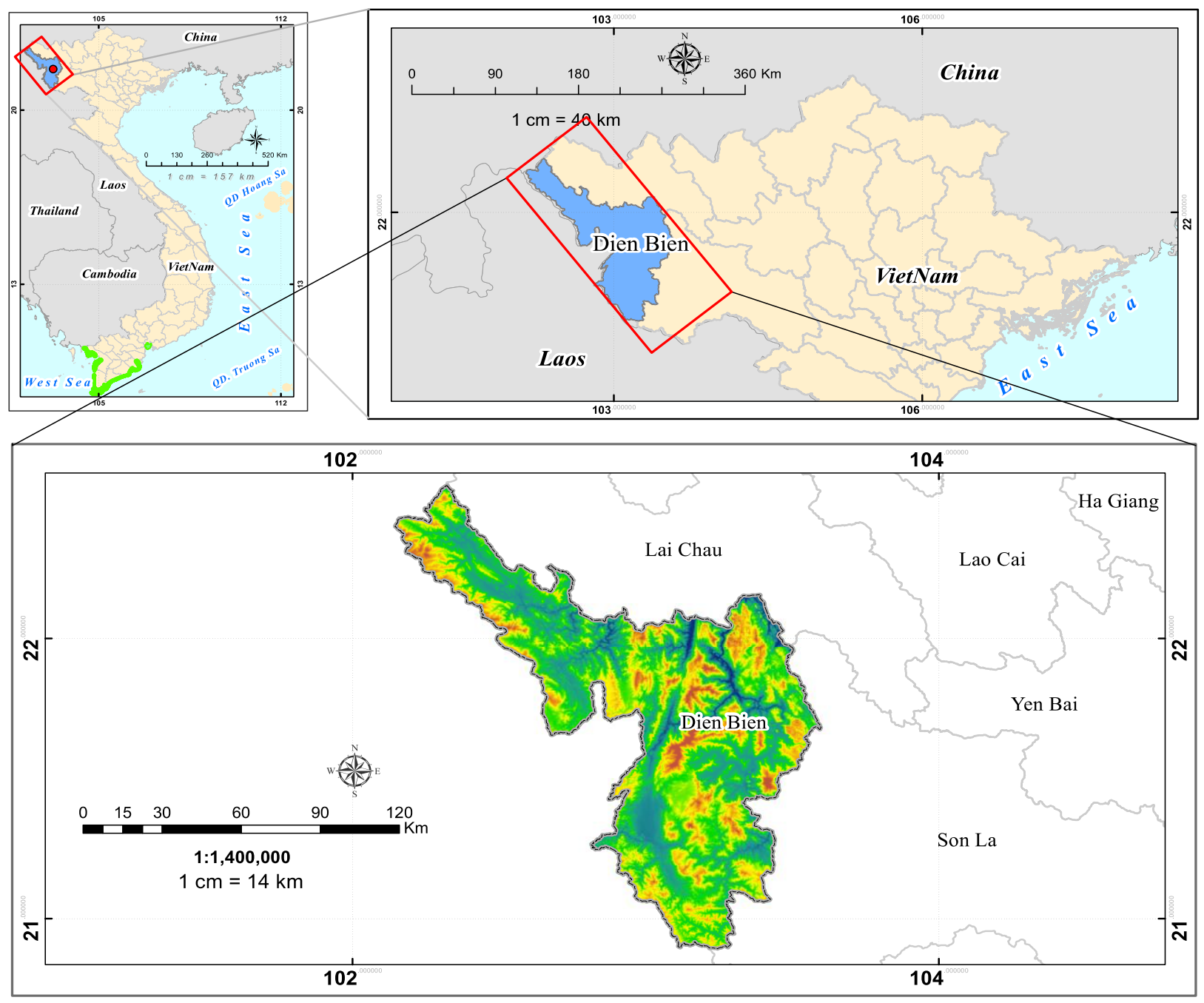

\section{Legend}

Province Boundary

Elevation (m)

Value High : 2184

Low : 137

Geographic Coordinate Systems

Name: GCS WGS 1984

Datum: D WGS 1984

Spheroid: WGS 1984

Figure 1. The study area in Dien Bien Province, Vietnam. 


\subsection{Datasets}

\subsubsection{Dependent variable (fire dataset)}

Dien Bien Province fire records were collected from the MODIS Collection 6 MCD64A1 at $500 \mathrm{~m}$ resolution for each fire that occurred between 2003 and 2016 [32]. MODIS records contained detailed information about the geographic location, size, start date and end date of each fire [32]. Only records of agricultural land fires were used for modelling the drivers of fire occurrence, which were discriminated from fires in non-agricultural lands (e.g., natural forest, plantation forest and other land-use categories) by determining agricultural land boundaries on Vietnam land use maps [28, 33]. Among all collected MODIS fire records $(n=8,312)$ we determined that 2,860 and 5,452 fires occurred on agricultural and non-agricultural land (34.4\% and $65.6 \%)$, respectively.

\subsubsection{Independent variables}

We considered four variable groups (fuel, weather, topographic and anthropogenic) to explain the occurrence of agricultural land fires throughout the study area (Table 1).

Fuel condition was estimated using a time series of the 2-band Enhanced Vegetation Index (EVI2), which was extracted from the MODIS Land Cover Dynamics Version 6 (MCD12Q2) Hierarchical Data Format 4 (HDF4) file_[34]. Of note is that EVI2 exhibited a stronger linear correlation with fuel moisture condition and fuel load in comparison to other remote sensed vegetation indices (e.g., Normalized Difference Vegetation Index) [35,36].

Weather condition included four variables: (1) daily temperature at 13:00 $\left({ }^{\circ} \mathrm{C}\right)$, (2) daily relative humidity at 13:00 (\%), (3) daily precipitation $(\mathrm{mm})$ and $(4)$ wind speed $(\mathrm{kph})$. Weather condition data were obtained for each fire presence and fire absence location from the three nearest weather stations within the study area [37].

Topographic condition included three variables: (1) elevation (m), (2) aspect $\left(0-360^{\circ}\right.$ classified into eight directions; Burrough \& McDonnell, 1998) and (3) slope $\left(0-90^{\circ}\right)$. Elevation data was extracted from the Global Digital Elevation Map, which was generated as part of the Shuttle Radar Topography Mission (SRTM) (https://search.earthdata.nasa.gov/search?q=SRTM) while aspect and slope data were generated from elevation data and resampled to the coarser resolution of the MODIS datasets $(500 \mathrm{~m})$.

Anthropogenic condition included two variables: (1) population density (per $\mathrm{km}^{2}$ ) and (2) distance $(\mathrm{m})$ to the nearest road [38-40]. Population density data was extracted from the gridded population of the world (GPW version 4), which provides population count and density at 30 arcsecond resolution (approx. $1 \mathrm{~km}$ ) on distribution maps [41]. Distances between each fire occurrence point and the nearest road were calculated by applying the ArcGIS spatial analysis Euclidian distance module (500 $\mathrm{m}$ resolution raster) to the digital road map of Dien Bien Province (Ministry of Agriculture and Rural Development [28].

All independent environmental condition variables in raster format (Table 1) were resampled into the same resolution $(500 \mathrm{~m})$ as the dependent variable (fire dataset; see Section 2.2.1). 
Table 1. Independent variables considered in the multivariate model of agricultural land fires that occurred within Dien Bien Province, Vietnam (2003 - 2016)

\begin{tabular}{|c|c|c|}
\hline Variables & Description & Format \\
\hline \multicolumn{3}{|l|}{ Fuel condition } \\
\hline EVI2 (EVI_Amplitude) & $\begin{array}{l}\text { The 2-band Enhanced Vegetation Index (Segment } \\
\text { maximum - minimum EVI2) }\end{array}$ & Raster \\
\hline Weather conditions & & Excel \\
\hline Rainfall & The rainfall for a given day $(\mathrm{mm})$ & \\
\hline Temperature & The temperature for a given day at $13.00\left({ }^{\circ} \mathrm{C}\right)$ & Excel \\
\hline Relative Humidity & The relative humidity at 13.00 for a given day (\%) & Excel \\
\hline Wind speed & The wind speed at 13.00 for a given day (kph) & Excel \\
\hline \multicolumn{3}{|l|}{ Topographic conditions } \\
\hline Elevation & Elevation $(\mathrm{m})$ & Raster \\
\hline Slope & Slope $\left(^{\circ}\right)$ & Raster \\
\hline Aspect & $\begin{array}{l}\text { North }\left(337.5-22.5^{\circ}\right), \text { Northeast }\left(22.5-67.5^{\circ}\right) \text {, East }(67.5 \text { - } \\
\left.112.5^{\circ}\right) \text {, Southeast }\left(112.5-157.5^{\circ}\right) \text {, South }\left(157.5-205.5^{\circ}\right) \text {, } \\
\text { Southwest }\left(205.5-247.5^{\circ}\right) \text {, West }\left(247.5-292.5^{\circ}\right) \text {, } \\
\text { Northwest }\left(247.5-337.5^{\circ}\right)\end{array}$ & Raster \\
\hline \multicolumn{3}{|l|}{ Anthropogenic conditions } \\
\hline Population density & The number people per $\mathrm{km}^{2}$ & Raster \\
\hline Distance to nearest road & $\begin{array}{l}\text { Distance from forest fire occurrence/non-occurrence to } \\
\text { the nearest road }(\mathrm{m})\end{array}$ & Raster \\
\hline
\end{tabular}

\subsection{Statistical Analysis}

All statistical analyses were conducted using R version 3.6.1 [42]. Modules used for data compilation, visualisation, transformation, analysis and storage included $p R O C$ [43], ggplot2 [44], rms [45], BMA [46], psych [47], compareGroups [48], and caret [49].

Descriptive analysis of fire occurrence data was assessed for meaningful temporal (months, years and season of occurrence) and spatial (vegetation types; Table 1) patterns.

We used logistic regression analysis to describe the effects of anthropogenic and environmental condition variables that drive agricultural land fires (i.e., fire presence versus fire absence). For fire presence the dataset described in Section 2.2.1 was used while for fire absence we randomly generated 3,180 non-fire points within the study area. Values for each independent variable (Table 1; see Section 2.2.2) were assigned to each fire presence and fire absence location before each location was converted into binary code (one and zero, respectively) and used as the dependent variable in logistic regression analysis.

Univariate logistic regression models were initially employed to determine the relationship between fire occurrence and each independent variable (Table 1). Multivariate logistic regression models were subsequently built using a backwards stepwise algorithm [50] based on the Akaike Information Criterion (AIC) [51,52] to determine the best model for predicting agricultural land fires. AIC values reflect model fit quality with more accurate models exhibiting smaller AIC values. Goodness of fit was also measured for each model using the area under curve (AUC) of the receiver operating characteristics (ROC) curve and the percentage of deviance explained [53-55]. AUC values range from $0.5-1$ with values $>0.7$ generally indicating reasonable predictive capability $[56,57]$. Higher AUC values reflect better models [58].

To assess the relative contribution of each independent environmental condition variable (Table 1) in the multivariate model we used the variable importance (varImp) function of the $R$ package caret [49], which computes the absolute value of the $\mathrm{z}$-statistic for each inputted variable. 


\section{Results}

\subsection{Temporal and spatial patterns}

During the study period 2,860 fires occurred on agricultural land (approx. 11\% of Dien Bien Province area), which exceeded the number of fires that occurred on natural forest $(n=2,637)$ and plantation forest $(n=17)$ lands despite these forested lands collectively covering approx. $40 \%$ of Dien Bien Province area (Figure 2a). Fire occurrence also varied by year with the most $(n=373)$ and least $(n$ = 26) during 2005 and 2008, respectively (Figure 2b). Furthermore, fires occurred most often during the dry season with spikes in February and March (Figure 2c).

\subsection{Driving factors of agricultural land fire occurrence}

All variables (fuel, weather, topographic and anthropogenic) yielded significant univariate models $(\mathrm{P}<0.05)$ except for one topographic condition variable (Northwest aspect $\mathrm{P}=0.24$; Table 2 ). Among these 16 significant environmental condition variables a positive and negative relationship (i.e., positive and negative coefficient) was observed for ten and seven of them, respectively (Table 2).

The multivariate logistic regression model (built using the 16 variables that were significant for univariate models with an AIC of 9,435.4 and AUC of 0.76 (Table 3). All environmental conditions (fuel, weather, topographic and anthropogenic) variables were significant within the multivariate model $(\mathrm{P}<0.05)$ except for three topographic condition variables (North, Northwest and Sou thwest; $\mathrm{P}$ $=0.55,0.096$ and 0.211 respectively; Table 4). Among these 14 significant environmental conditions variables a positive and negative relationship was observed for eight and six of them, respectively (Table 4).

Each independent environmental condition variable contributed to the multivariate logistic regression model to a unique degree (Table 5). More specifically, EVI2 was the most important environmental condition variable $(20.96 \%)$ followed by elevation $(14.05 \%)>$ temperature $(12.38 \%)>$ relative humidity $(9.46 \%)>$ wind speed $(7.48 \%)>$ rainfall $(5.96 \%)>$ distance to nearest road $(5.69 \%)>$ slope $(5.23 \%)>$ south aspect $(3.44 \%)>$ southeast aspect $(3.09 \%)>$ northeast aspect $(2.33 \%)$ and population density $(2.33 \%)>$ north aspect $(1.98 \%)>$ southwest aspect $(1.66 \%)>$ west aspect $(1.24 \%)>$ northwest aspect $(0.6 \%)$. 

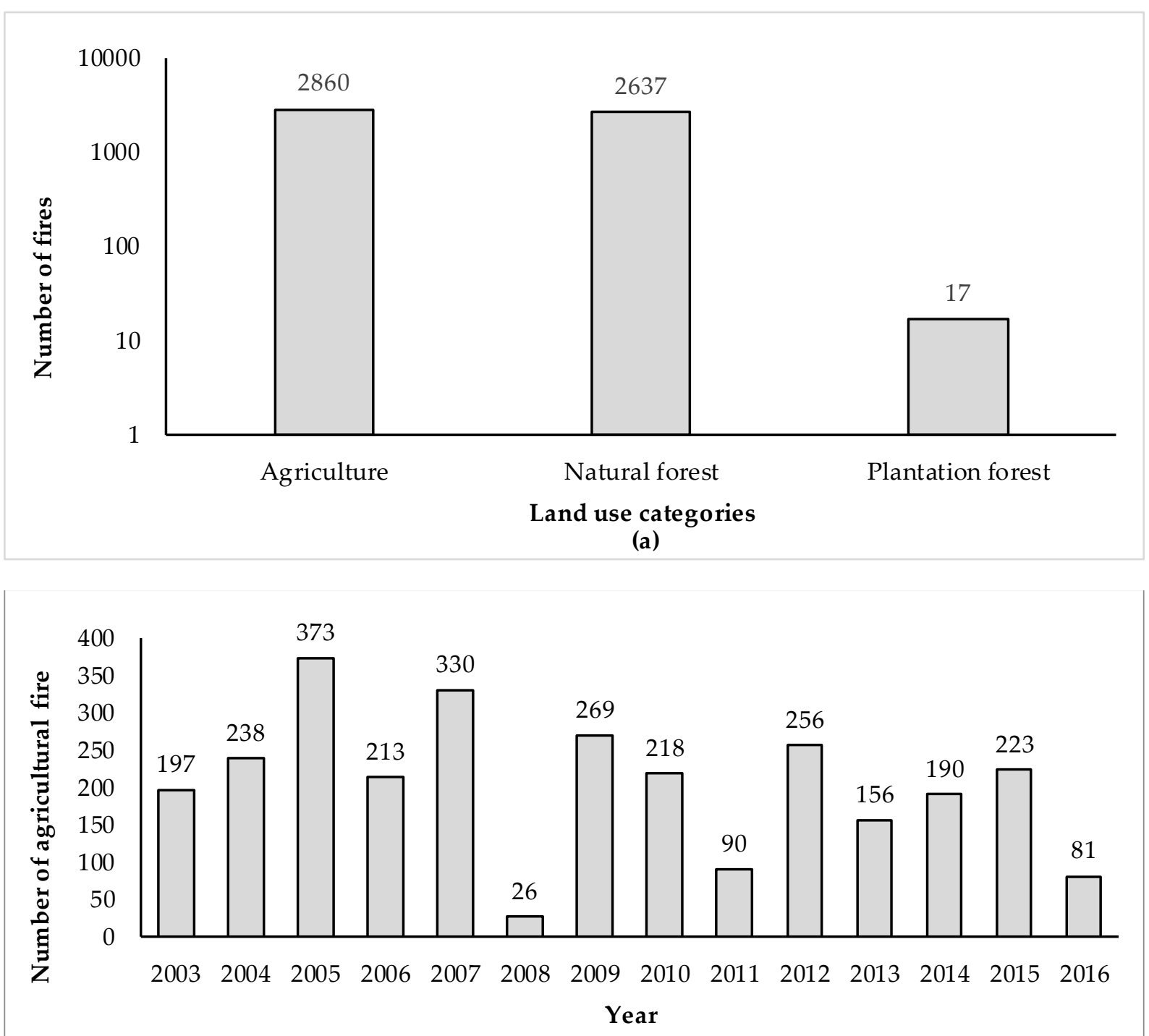

(b)

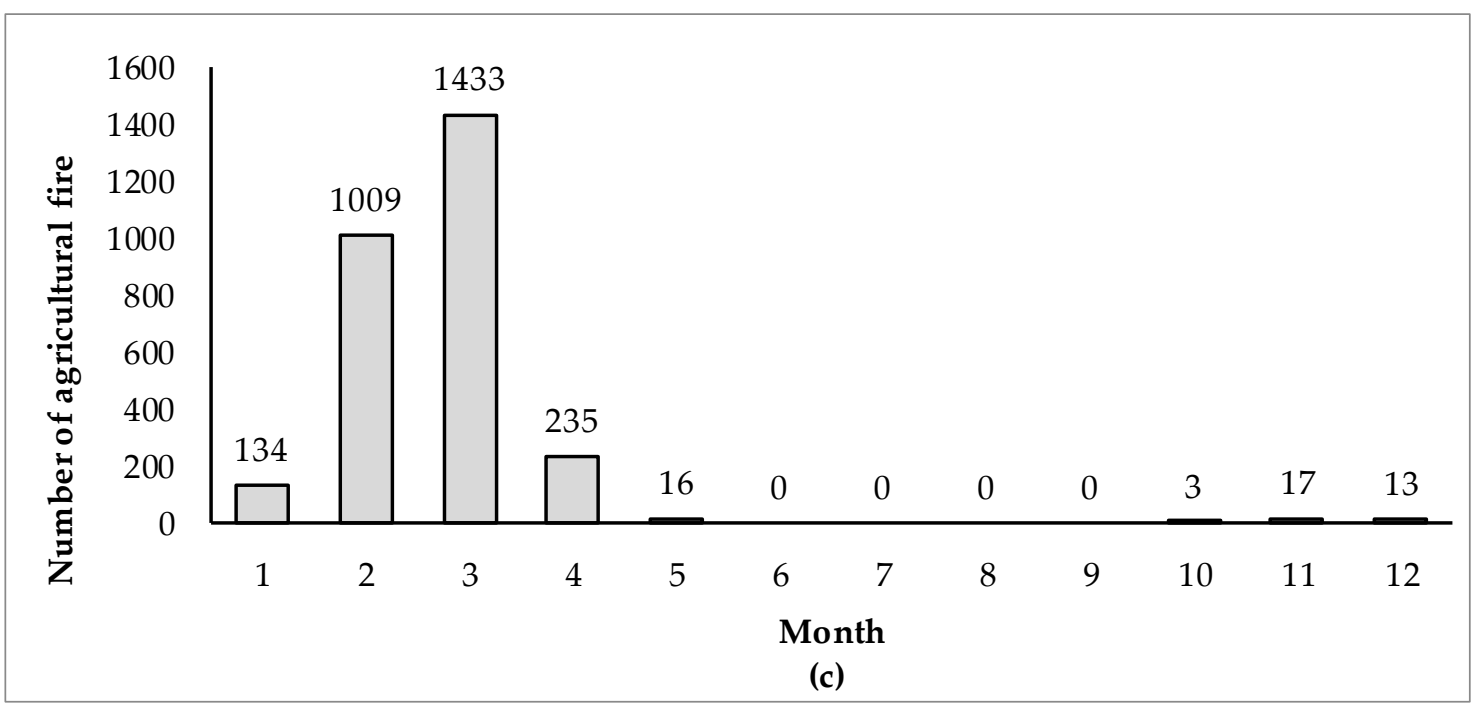

Figure 2. Distribution of fire occurrence in Dien Bien Province by land use type (a), year (b), and month (c). Note that Y-axis of Panel A is $\log 10$ scale. 
Table 2. Univariate models for predicting agricultural land fires in Dien Bien Province, Vietnam (2003 - 2016) based on each independent environmental condition variable

\begin{tabular}{|c|c|c|c|c|c|c|}
\hline Variables & Coefficients & Std. Error & $Z$ value & $\operatorname{Pr}(>|z|)$ & $\mathrm{AIC}$ & AUC \\
\hline \multicolumn{7}{|l|}{ Fuel condition } \\
\hline EVI2 & $6.2 \mathrm{e}-04$ & $3 e-05$ & 20.43 & $<2 \mathrm{e}-16^{* * *}$ & 10683 & 63.86 \\
\hline \multicolumn{7}{|l|}{ Weather conditions } \\
\hline Temperature & 0.14 & 0.006 & 22.35 & $<2 \mathrm{e}-16^{* * *}$ & 10539 & 66.48 \\
\hline Rainfall & -0.09 & 0.008 & -10.82 & $<2 \mathrm{e}-16^{* * *}$ & 10912 & 56.51 \\
\hline Relative Humidity & -0.05 & 0.002 & -25.23 & $<2 \mathrm{e}-16^{* * *}$ & 10404 & 66.73 \\
\hline Wind speed & 0.06 & 0.005 & 11.96 & $<2 \mathrm{e}-16^{* * *}$ & 10987 & 55.38 \\
\hline \multicolumn{7}{|c|}{ Topographic conditions } \\
\hline Elevation & 0.001 & $8.88 \mathrm{e}-05$ & 12.8 & $<2 \mathrm{e}-16^{* * *}$ & 10965 & 59.3 \\
\hline Slope & -0.009 & 0.003 & -3 & $0.003^{* *}$ & 11123 & 52.23 \\
\hline Aspects & & & & & 11036 & 56.6 \\
\hline Intercept & -0.85 & 0.06 & -13.12 & $<2 \mathrm{e}-16^{* * *}$ & & \\
\hline North & -0.22 & 0.0954 & -2.33 & $0.02^{*}$ & & \\
\hline Northeast & -0.3 & 0.0953 & -3.16 & $0.0015^{*}$ & & \\
\hline South & 0.4 & 0.0879 & 4.54 & $5.59 \mathrm{e}-06^{* * *}$ & & \\
\hline Southwest & 0.28 & 0.0906 & 3.08 & $0.002^{* *}$ & & \\
\hline West & 0.2 & 0.092 & 2.15 & $0.03^{*}$ & & \\
\hline Southeast & 0.32 & 0.088 & 3.65 & $0.0002^{* * *}$ & & \\
\hline Northwest & 0.11 & 0.0927 & 1.16 & 0.24 & & \\
\hline \multicolumn{7}{|c|}{ Anthropogenic conditions } \\
\hline Population density & -0.001 & 0.0004 & -2.72 & $0.006^{* *}$ & 11123 & 50.21 \\
\hline $\begin{array}{l}\text { Distance to nearest } \\
\text { road }\end{array}$ & $6.8 \mathrm{e}-05$ & $1.5 e-05$ & 4.47 & $7.89 e-06^{* * *}$ & 11112 & 54.65 \\
\hline
\end{tabular}

Table 3. Performance of best multivariate model for predicting agricultural land fires in Dien Bien Province, Vietnam (2003-2016)

\begin{tabular}{|c|c|c|c|}
\hline Model & d.f. (\%) & AIC & AUC \\
\hline $\begin{array}{l}\text { Temperature +Rainfall + Relative humidity }+ \text { Wind speed } \\
+ \text { Elevation }+ \text { Slope }+ \text { Aspects }+ \text { EVI } 2+\text { Population density } \\
+ \text { Distance to nearest road }\end{array}$ & 16 & 9435.4 & 0.76 \\
\hline
\end{tabular}

d.f., percentage of deviance explained; AIC, Akaike information criterion; AUC, area under the receiver operating characteristics curve. 
Table 4. Estimates for each independent environmental condition variable from multivariate model for predicting agricultural land fires in Dien Bien Province, Vietnam (2003 - 2016)

\begin{tabular}{|c|c|c|c|c|}
\hline Variable & Coefficients & Std. Error & z value & $\operatorname{Pr}(>|Z|)$ \\
\hline Intercept & -5.67 & 0.38 & -14.85 & $<2 \mathrm{e}-16^{* * *}$ \\
\hline \multicolumn{5}{|l|}{ Fuel condition } \\
\hline EVI2 & -0.0007 & $3.36 \mathrm{e}-05$ & 20.96 & $<2 \mathrm{e}-16^{* * *}$ \\
\hline \multicolumn{5}{|l|}{ Weather conditions } \\
\hline Temperature & 0.098 & 0.008 & 12.38 & $<2 \mathrm{e}-16^{* * *}$ \\
\hline Rainfall & -0.047 & 0.0078 & -5.96 & $2.51 \mathrm{e}-09^{* * *}$ \\
\hline Relative humidity & -0.026 & 0.0027 & -9.46 & $<2 \mathrm{e}-16^{* * *}$ \\
\hline Wind speed & 0.045 & 0.006 & 7.48 & $7.2 \mathrm{e}-14^{* * *}$ \\
\hline \multicolumn{5}{|l|}{ Topographic conditions } \\
\hline Elevation & 0.0015 & 0.0001 & 14.05 & $<2 \mathrm{e}-16^{* * *}$ \\
\hline Slope & -0.02 & 0.0036 & -5.24 & $1.64 \mathrm{e}-07^{* * *}$ \\
\hline \multicolumn{5}{|l|}{ Aspects } \\
\hline North & -0.21 & 0.104 & -1.99 & $0.047^{*}$ \\
\hline Northeast & -0.24 & 0.104 & -2.34 & $0.02^{*}$ \\
\hline Northwest & 0.06 & 0.102 & 0.6 & 0.55 \\
\hline South & 0.33 & 0.097 & 3.44 & $0.0006^{* * *}$ \\
\hline Southeast & 0.305 & 0.098 & 3.1 & $0.002^{* *}$ \\
\hline Southwest & 0.167 & 0.1 & 1.66 & 0.096 \\
\hline West & 0.127 & 0.102 & 1.25 & 0.211 \\
\hline \multicolumn{5}{|l|}{ Anthropogenic conditions } \\
\hline Population density & -0.0011 & 0.0005 & -2.33 & $0.02^{*}$ \\
\hline Distance to nearest road & 0.0001 & $1.77 \mathrm{e}-05$ & 5.69 & $1.25 \mathrm{e}-08^{* * *}$ \\
\hline
\end{tabular}

${ }^{* * *} \mathrm{P}<0.001 ;{ }^{* *} \mathrm{P}<0.01 ;{ }^{*} \mathrm{P}<0.05$

Table 5. Importance of each independent environmental condition variable in the multivariate logistic regression model for predicting agricultural land fires in Dien Bien Province, Vietnam (2003 - 2016)

\begin{tabular}{lc}
\hline Variable & Importance ${ }^{1}$ \\
\hline EVI2 & 20.96 \\
Elevation & 14.05 \\
Temperature & 12.38 \\
Relative humidity & 9.46 \\
Wind speed & 7.48 \\
Rainfall & 5.96 \\
Distance to nearest road & 5.69 \\
Slope & 5.23 \\
South & 3.44 \\
Southeast & 3.09 \\
Northeast & 2.33 \\
Population density & 2.33 \\
North & 1.98 \\
Southwest & 1.66 \\
West & 1.24 \\
Northwest & 0.6 \\
\hline
\end{tabular}

\footnotetext{
1 Computed absolute value of $z$-statistic (see Section 2.3.3)
} 


\section{Discussion}

Most agricultural land fires within Dien Bien Province were found to have occurred between January and April with peaks in February and March (i.e., predominantly during dry season) as expected due to low rainfall and humidity as well as prevailing Foehn (hot dry) winds [26]. Interestingly, agricultural land fire frequency was lower during the two first months of the dry season (November and December) than during the first month of the wet season (April). One explanation could be that vegetation was still sufficiently wet at the beginning of the dry season (i.e., not readily combustible) whereas vegetation was still sufficiently dry at in the beginning of the wet season (i.e., readily combustible). Of note is that the observed seasonality of agricultural land fires (January - April) was shorter than previously reported for forested land fires (November - May) (Ngoc Thach et al., 2018).

The number of agricultural land fires was higher than the number of forested land fires (Figu re 2a) despite Dien Bien Province containing approx. four times more forested land (Ministry of Agriculture and Rural Development, 2016). This observation highlights the necessity for government policies that provide effective management (i.e., mitigation) of agricultural land fires in addition to the current fire management policies that are primarily focused on forest fires.

Our analyses demonstrated that increased temperature, wind speed, elevation and EVI2 while decreased rainfall and humidity lead to the increased potential for agricultural land fires. The observed effects of fuel and weather conditions on agricultural land fire occurrence were generally consistent with those found to predict fire occurrence on other landscapes $[59,60]$. The significant relationships between agricultural land fire occurrence and two topographic conditions (elevation and slope) were also consistent with previous studies that demonstrated the more rapid drying of surface fuel sources in locations with higher elevations and slopes due to the corresponding increase in drainage efficiency and sunlight exposure, respectively [12, 61-63].

The negative correlation between population density and agricultural land fire occurrence probability was unexpected given that was inconsistent with previous studies demonstrated a positive correlation between this anthropogenic condition and wildfire occurrence probability [38$40,64,65]$. This discrepancy could be due to the fact that agricultural land fires generally occur in unpopulated regions and tend to be intentionally ignited by humans (depending on region-specific agriculture type) whereas wildfires tend to occur near population centers [21]. Dien Bien Province residents mostly live in the valleys between mountain ranges with villages surrounded by wetland crops (e.g. rice and Meize crops) that are not generally susceptible to fires; how ever, agricultural land fires that do occur tend to be in remote and unmanaged (i.e., not irrigated) shrub lands that have been converted into pastures, grazing areas, and other crops. The positive correlation between distance to nearest road and agricultural land fire occurrence probability was expected given the increased population density near roads in Dien Bien Province and, thus, the more prompt and forceful response to any fires that do occur.

Of all the independent environmental condition variables assessed, fuel condition (EVI2) was found to be the most important in the multivariate linear regression model of agricultural land fire occurrence in Dien Bien Province (Table 5). Unlike forest vegetation, the most common agricultural land vegetation in Dien Bien Province is the grass tree, which is known to create a continuous layer of highly combustible fuel [66] and is highly susceptible to fire [67]. Moreover, EVI2 has been demonstrated to have a strong fire prediction capability for grasslands, shrublands, forests and heathlands in other regions in the world $[67,68]$ because this fuel condition predictor is significantly correlated with in situ live, dead and litter fuel moisture (Caccamo et al., 2011) and, thus, can predict live and dead fuel moisture better than the commonly used Keetch Byram Drought Index (KBDI) predictors [67]. Despite unique level of importance for each independent variable (Table 5) the best multivariate linear regression model for predicting agricultural land fires in Dien Bien Province (i.e., best AIC score) considered data collected for 16 of 17 independent variables across four en vironmental conditions (fuel, weather, topographic and anthropogenic). As such, we propose that future studies aimed at modelling the probability of fire occurrence collect data for similarindependent variables that span the same or additional environmental conditions. 
In Vietnam, the Forest Fire Danger Rating System (FFDRS) uses the Modified Nesterov Index (MNI) to predict the occurrence of fires on forested land based on weather conditions only (e.g., temperature and rainfall); however, this model not comprehensive enough to accurately predict agricultural land fires because data for independent variables across fuel, topographic and anthropogenic conditions are also required. Of note is that the fuel condition, which is not considered in the currently utilized FFDRS model, is more important than weather conditions for accurate agricultural land fire prediction. The novel multivariate linear regression model developed in this study can be utilized to develop a fire danger rating system that is specific to agricultural lands and, in so doing, provide agricultural land managers with new tools for making accurate and effective decisions. Lastly, we encourage future studies to establish region-specific models for accurate agricultural land fire prediction.

\section{Conclusions}

Understanding the seasonality and environmental conditions that drive agricultural land fires is of critical importance for improved agricultural land fire management effectiveness and, consequentially, reduced frequency and/or severity of fires on the agricultural sector. Our analysis of satellite remote sensed data revealed that agricultural land fires occurred more frequently than forested land fires within Dien Bien Province between 2003 and 2016. Correlations between temporal and spatial variations and fuel, weather, topographic and anthropogenic conditions were also observed among Dien Bien Province agricultural land fires. Among the assessed environmental conditions, fuel and weather are the most important for the agricultural land fire prediction multivariate model. While the multivariate model presented herein furthers our understanding about the primary driving factors of agricultural land fires, future research should aim to determine region-specific prediction models for agricultural land fires given the limited knowledge about how these fires compare to wild fires, especially under predicted climate change scenarios (e.g., hotter and dried). Lastly, future studies should consider the role of additional anthropogenic conditions (e.g., type of agricultural cultivation and harvest) given our observation of positive and negative correlations between the occurrence of agricultural land fires and human activities (distance to nearest road and population density, respectively) within Dien Bien Province, Vietnam between 2003 and 2016.

Funding: This research received no external funding

Acknowledgments: The authors would like to thank Professor Tuan V Nguyen at St Vincent's Clinical School, UNSW Medicine, University of New South Wale (UNSW) for his assistance with data analysis. We would like to thank Richard C. Edmunds for his assistance with English editing.

\section{References}

1. Bruinsma, J., ed. World agriculture: towards 2015/2030, An FAO persective 2003, Earthscan Publications Ltd 120 Pentonville Road London, N1 9JN, UK: Food and Agriculture Organization (FAO).

2. UNEP. Ten impacts of the Australian bushfires. 2020 [cited 3 July 2020; Available from: https://www.unenvironment.org/news-and-stories/story/ten-impacts-australian-bushfires.

3. Korontzi, S., J. McCarty, and C. Justice, Monitoring Agricultural Burning in the Mississippi River Valley Region from the Moderate Resolution Imaging Spectroradiometer (MODIS). Journal of the Air \& Waste Management Association, 2008. 58(9): p. 1235-1239.

4. Korontzi, S., et al., Global distribution of agricultural fires in croplands from 3 years of Moderate Resolution Imaging Spectroradiometer (MODIS) data. Global Biogeochemical Cycles, 2006. 20(2).

5. Tulbure, M.G., et al., Spatial and temporal heterogeneity of agricultural fires in the central United States in relation to land cover and land use. Landscape Ecology, 2011. 26(2): p. 211-224.

6. Bessie, W. and E. Johnson, The relative importance of fuels and weather on fire behavior in subalpine forests. Ecology, 1995. 76(3): p. 747-762.

7. Bowman, D., Balch, J., Artaxo, P., Bond, W. J., Cochrane, M. A., D'antonio, C.M., DeFries, R.,Johnston, F.H., Keeley, J. E. \& Krawchuk, M. A., The human dimension of fire regimes on Earth. Journal of biogeography, 2011.38(12): p. 2223-2236. 
8. Harvey, B.J., D.C. Donato, and M.G. Turner, Drivers and trends in landscape patterns of stand-replacing fire in forests of the US Northern Rocky Mountains (1984-2010). Landscape Ecology, 2016. 31(10): p. 23672383.

9. Parks, S.A., Holsinger, Lisa M., Panunto, Matthew H., Jolly, W Matt., Dobrowski, Solomon Z \&Dillon, Gregory K, High-severity fire: evaluating its key drivers and mapping its probability across western US forests. Environmental research letters, 2018. 13(4): p. 044037.

10. Taylor, S.W., et al., Wildfire prediction to inform management: statistical science challenges. Statistical Science, 2013: p. 586-615.

11. Bradstock, R.A., A biogeographic model of fire regimes in Australia: current and future implications. Global Ecology and Biogeography, 2010. 19(2): p. 145-158.

12. Fang, L., et al., Quantifying influences and relative importance of fire weather, topography, and vegetation on fire size and fire severity in a Chinese boreal forest landscape. Forest Ecology and Management, 2015. 356: p. $2-12$.

13. Lee, H.-J., Y. Choi, and S.-W. Lee, Complex relationships of the effects of topographic characteristics and susceptible tree cover on burn severity. Sustainability, 2018. 10(2): p. 295.

14. Birch, D.S., et al., Vegetation, topography and daily weather influenced burn severity in central Idaho and western Montana forests. Ecosphere, 2015. 6(1): p. 1-23.

15. Goldammer, J.G., History of equatorial vegetation fires and fire research in Southeast Asia before the 1997-98 episode: a reconstruction of creeping environmental changes. Mitigation and Adaptation Strategies for Global Change, 2007. 12(1): p. 13-32.

16. Stefan Hauser, L.N., Slash-and-Burn Agriculture, Effects of, in Encyclopedia of Biodiversity (Second Edition), S.A. Levin, Editor. 2013: Academic Press. p. 551-562.

17. Bekar, İ. and Ç. Tavşanoğlu, Modelling the drivers of natural fire activity: the bias created by cropland fires. International Journal of Wildland Fire, 2017. 26(10): p. 845-851.

18. Curt, T., et al., Understanding fire patterns and fire drivers for setting a sustainable management policy of the New-Caledonian biodiversity hotspot. Forest Ecology and Management, 2015. 337: p. 48-60.

19. Pausas, J.G. and E. Ribeiro, The global fire-productivity relationship. Global Ecology and Biogeography, 2013. 22(6): p. 728-736.

20. Archibald, S., et al., Defining pyromes and global syndromes of fire regimes. Proceedings of the National Academy of Sciences, 2013. 110(16): p. 6442-6447.

21. Chuvieo, E.G., Louis Justice, Chris Global characterization of fire activity: toward defining fire regimes from Earth observation data. Global Change Biology, 2008. 14(7): p. 1488-1502.

22. Adámek, M., et al., Drivers of forest fire occurrence in the cultural landscape of Central Europe. Landscape Ecology, 2018. 33(11): p. 2031-2045.

23. Ganteaume, A., et al., A Review of the Main Driving Factors of Forest Fire Ignition Over Europe. Environmental management, 2012. 51.

24. Su, Z., et al., Comparative analysis of spatial variation in forest fire drivers between boreal and subtropical ecosystems in China. Forest Ecology and Management, 2019. 454: p. 117669.

25. General statistics office of Vietnam. Area and population. 2011; Available from: https://www.gso.gov.vn/default.aspx?tabid=387\&idmid=3\&ItemID=12875.

26. Van, N.K., Climatic zoning of the Bac Bo mountainous provinces and Western Thanh Nghe. Vietnam Journal of Earth Sciences, 2015. 37(3): p. 204-212.

27. DienBien portal. Overview of DienBien. 2020; Available from: http://www.dienbien.gov.vn/portal/Pages/Tong-quan-ve-Dien-Bien.aspx (accessed 2nd July, 2020).

28. Ministry of Agriculture and Rural Development, National forest inventory map. 2016.

29. Phuong, V.T., et al., Forest ecological stratification in Vietnam. Techniques and Science Publishing House, Hanoi, Vietnam, 2012: p. 139.

30. Le, T.H., et al., Vegetation fires and air pollution in Vietnam. Environmental pollution, 2014. 195: p. 267275.

31. Doanh, L.S., Bao, T.Q., Impact of climate change on forest fire risk in Vietnam. Journal of Agriculture and Rural Development, 2014. 7: p. 113-118 (in Vietnamese).

32. Andela, N., et al., The Global Fire Atlas of individual fire size, duration, speed and direction. Earth System Science Data, 2019. 11(2).

33. Ministry of Agriculture and Rural Development, Circular No.34/2009/TT-BNNPTNT dated 10 June, 2009 on criteria for forest identification and classification (in Vietnamese). 2009.

34. Gray, J., et al., Global Land Surface Phenology from MODIS: Collection 6 Products. Remote Sens. Environ, 2019.

35. Myoung, B., et al., Estimating live fuel moisture from MODIS satellite data for wildfire danger assessment in Southern California USA. Remote Sensing, 2018. 10(1): p. 87. 
36. Roberts, D., et al., Evaluation of Airborne Visible/Infrared Imaging Spectrometer (AVIRIS) and Moderate Resolution Imaging Spectrometer (MODIS) measures of live fuel moisture and fuel condition in a shrubland ecosystem in southern California. Journal of Geophysical Research: Biogeosciences, 2006. 111(G4).

37. Vietnam Center of Hydro-meteorological Data, Climatic data. 2003-2016.

38. Ye, T., et al., Factor contribution to fire occurrence, size, and burn probability in a subtropical coniferous forest in East China. PloS one, 2017. 12(2).

39. Matin, M.A., et al., Understanding forest fire patterns and risk in Nepal using remote sensing, geographic information system and historical fire data. International journal of wildland fire, 2017. 26(4): p. 276-286.

40. Kwak, H., et al., Estimating the spatial pattern of human-caused forest fires using a generalized linear mixed model with spatial autocorrelation in South Korea. International Journal of Geographical Information Science, 2012. 26(9): p. 1589-1602.

41. Center for International Earth Science Information Network, C.U.C., Documentation for the Gridded Population of the World, Version 4 (GPWv4), Revision 11 Data Sets.2018, NASA Socioeconomic Data and Applications Center (SEDAC).

42. Team, R.C., $R$ : a language and environment for statistical computing computer program, version 3.6. 1. R Core Team, Vienna, Austria, 2019.

43. Robin, X., et al., pROC: an open-source package for $R$ and $S+$ to analyze and compare ROC curves. BMC bioinformatics, 2011. 12(1): p. 77.

44. Wickham, H., ggplot2: elegant graphics for data analysis. 2016: Springer.

45. Harrell Jr, F.E., M.F.E. Harrell Jr, and D. Hmisc, Package 'rms'. Vanderbilt University, 2019. 229.

46. Raftery, A., et al., Package 'BMA'. 2020.

47. Revelle, W. and M.W. Revelle, Package 'psych'. The Comprehensive R Archive Network, 2015.

48. Subirana, I., et al., Package 'compareGroups'. 2020.

49. Kuhn, M., Wing, J., Weston, S., Williams, A., Keefer, C., Engelhardt, A., Cooper, T., Mayer, Z., Kenkel, B. \& Team, R.C., Package 'caret'. The R Journal, 2020.

50. Venables, W.N. and B.D. Ripley, Modern applied statistics with S-PLUS, 2nd ed. 1999: Springer Science \& Business Media.

51. Akaike, H., A new look at the statistical model identification. IEEE transactions on automatic control, 1974. 19(6): p. 716-723.

52. Akaike, H., Information theory and an extension of the maximum likelihood principle, in Selected papers of hirotugu akaike. 1998, Springer. p. 199-213.

53. Chang, Y., Zhu, Z., Bu, R., Chen, H., Feng, Y., Li, Y., Hu, Y. \& Wang, Z., Predicting fire occurrence patterns with logistic regression in Heilongjiang Province, China. Landscape Ecology, 2013. 28(10): p. 19892004.

54. Guo, F., et al., Understanding fire drivers and relative impacts in different Chinese forest ecosystems. Science of the Total Environment, 2017. 605: p. 411-425.

55. Jiménez-Valverde, A., Insights into the area under the receiver operating characteristic curve (AUC) as a discrimination measure in species distribution modelling. Global Ecology and Biogeography, 2012. 21(4): p. 498-507.

56. Fawcett, T., An introduction to ROC analysis. Pattern recognition letters, 2006. 27(8): p. 861-874.

57. Swets, J.A., Measuring the accuracy of diagnostic systems. Science, 1988. 240(4857): p. 1285-1293.

58. Del Hoyo, L.V., M.P.M. Isabel, and F.J.M. Vega, Logistic regression models for human-caused wildfire risk estimation: analysing the effect of the spatial accuracy in fire occurrence data. European Journal of Forest Research, 2011. 130(6): p. 983-996.

59. Penman, T.D., R.A. Bradstock, and O. Price, Modelling the determinants of ignition in the Sydney Basin, Australia: implications for future management. International Journal of Wildland Fire, 2013. 22(4): p. 469478.

60. Tien Bui, D., N.-D. Hoang, and P. Samui, Spatial pattern analysis and prediction of forest fire using new machine learning approach of Multivariate Adaptive Regression Splines and Differential Flower Pollination optimization: A case study at Lao Cai province (Viet Nam). Journal of Environmental Management, 2019. 237: p. 476-487.

61. Dillon, G.K., et al., Both topography and climate affected forest and woodland burn severity in two regions of the western US, 1984 to 2006. Ecosphere, 2011. 2(12): p. 1-33.

62. Holden, Z.A., P. Morgan, and J.S. Evans, A predictive model of burn severity based on 20-year satelliteinferred burn severity data in a large southwestern US wilderness area. Forest Ecology and Management, 2009. 258(11): p. 2399-2406.

63. Cansler, C.A. and D. McKenzie, Climate, fire size, and biophysical setting control fire severity and spatial pattern in the northern Cascade Range, USA. Ecological Applications, 2014. 24(5): p. 1037-1056. 
64. Ganteaume, A. and M. Jappiot, What causes large fires in Southern France. Forest Ecology and Management, 2013. 294: p. 76-85.

65. Badia, A., P. Serra, and S. Modugno, Identifying dynamics of fire ignition probabilities in two representative Mediterranean wildland-urban interface areas. Applied Geography, 2011. 31(3): p. 930-940.

66. LaRosa, A.M., et al., eds. Fire and nonnative invasive plants in the Hawaiian Islands Bioregion. Wildland fire in ecosystems: Fire and nonnative invasive plants, ed. K. Zouhar, et al. 2008: U.S. Department of Agriculture, Forest Service, Rocky Mountain Research Station, Ogden, UT, pp. 225-242.

67. Litton, C.M. and L.M. Ellsworth, Improved wildfire prediction using remote sensing technology on guinea grasslands in Hawaii - Final Report to the Joint Fire Science Program. FSP Project No. 11-3-1-12. 2013: Honolulu, HI: University of Hawaii-Manoa. 30 p.

68. Caccamo, G., et al., Monitoring live fuel moisture content of heathland, shrubland and sclerophyll forest in south-eastern Australia using MODIS data. International Journal of Wildland Fire, 2012. 21(3): p. 257-269. 